\title{
Control of single crystal morphology of SBA-1 mesoporous silica
}

\author{
Man-Chien Chao, ${ }^{a}$ Da-Shin Wang, ${ }^{b}$ Hong-Ping Lin ${ }^{*}{ }^{b}$ and Chung-Yuan $\mathrm{Mou}^{a}$ \\ ${ }^{a}$ Department of Chemistry, National Taiwan University, Taipei 106 Taiwan, \\ ${ }^{b}$ Department of Chemistry, National Cheng Kung University, Tainan 701 Taiwan,
}

Received 10th October 2003, Accepted 20th October 2003

First published as an Advance Article on the web 31st October 2003

SBA-1 mesoporous silica has been synthesized in different crystal shapes from $\mathrm{C}_{18} \mathrm{TMACl}$-sodium silicate$\mathrm{H}_{2} \mathrm{SO}_{4}-\mathrm{H}_{2} \mathrm{O}$ at $\mathrm{pH}$ values between 1.0 and 2.0.

Recently, faceted single crystals of mesoporous silica of various mesostructures (e.g. MCM-48, SBA-1, SBA-3 and SBA-16) have received increasing attention. ${ }^{1-10}$ Aside from the intrinsic value of understanding the crystal growth process, faceted single crystals of mesoporous silica may be good matrix materials for making micron-lasers due to their well-defined internal optical gallery mode. ${ }^{11,12}$ Recently, Liu and coworkers further showed large hierarchical structures of mesoporous silica may be built from uniform small single crystals. ${ }^{13}$ However, the few reported methods of making symmetrically shaped single crystals of mesoporous materials do not reveal the underlying principle. There is a lack of a systematic approach. Compared to microporous zeolites, the formation of single crystals of mesoporous silica is generally more difficult due to the low energy cost in the formation of defects.

Among the mesoporous silicas, SBA-1 is the most interesting due to its highly symmetric $3 \mathrm{D}$ cubic $P m \overline{3} n$ structure. ${ }^{5-8,13-16} \mathrm{It}$ is synthesized from the acid hydrolysis of TEOS with the surfactant cetyltriethylammonium bromide (CTEABr). The surfactant packing parameters may be delicately varied to control both mesostructure ${ }^{17}$ and pore size. ${ }^{18} \mathrm{~A}$ single crystal with an external cubo-octahedron morphology has been made. ${ }^{19,20}$ In this communication, we wish to vary and control the morphology of a single crystal of SBA-1. Here, we propose a new synthetic method to prepare the SBA-1 mesoporous silica crystals from the $\mathrm{C}_{18}$ TMACl-sodium silicate- $\mathrm{H}_{2} \mathrm{O}$ components at $\mathrm{pH}$ values in the range of 1.0-2.0 around the isoelectric point (IEP) of silica. Due to the $\mathrm{pH}$-dependence of the silica condensation rate, the shapes of the surfactanttemplated SBA-1 mesoporous silica crystals show an evolution from sphere $\rightarrow$ decaoctahedron $\rightarrow$ truncated cube $\rightarrow$ cube as the $\mathrm{pH}$ value decreases from 1.0 to 2.0 .

A slow growth rate is the fundamental requirement for formation of crystals with well-shaped morphology. Based on the silica chemistry, the silica condensation rate is slowest and surface charge is electrically neutral around the isoelectric point of silica at $\mathrm{pH} \sim 2.0$. Thus normally one uses TEOS as silica source in standard acid synthesis. In contrast, here a very dilute acidified sodium silicate solution of $\mathrm{pH}$ value $=1.0-2.0$ was used directly as the silica source. Thus, the quaternary ammonium surfactant silica self-assembling mesostructure can be formed slowly because of the weak hydrogen-bonding interaction $\left(\mathrm{S}^{+} \mathrm{X}^{-} \mathrm{I}^{0}\right)$ and the slow condensation of silica species. $\dagger$

Fig. 1A shows the XRD patterns of the calcined mesoporous silica obtained from samples with the same chemical composition at $\mathrm{pH}$ values of 1.0, 1.5, 1.8 and 2.0. All samples possess sharp XRD peaks characteristic of the three-dimensional cubic mesostructure $(P m \overline{3} n)$ of SBA-1 mesoporous silica. Within the $\mathrm{pH}$ range of 1.0-2.0 the surfactant-silica self-assembly rate is slow enough to allow $P m \overline{3} n$ globular arrays in the dilute solution. Furthermore, the textural properties of all samples were analyzed using $\mathrm{N}_{2}$ adsorption-desorption isotherms (Fig. 1B). One can clearly see a sharp capillary condensation at $P / P_{0}$ around 0.3 and a high absorption volume of about 400 $500 \mathrm{~cm}^{3} \mathrm{~g}^{-1}$, STP. All samples also have high BET surface areas of $1000-1200 \mathrm{~m}^{2} \mathrm{~g}^{-1}$ and pore sizes of $2.5-2.8 \mathrm{~nm}$ without microporosity. This is the first time SBA-1 mesoporous silica has been synthesized using sodium silicate as the silica source. Because of the dilute conditions used in the synthesis, there is more counterion dissociation which favors spherical micelles, even with the smaller trimethyl-head group of $\mathrm{C}_{18} \mathrm{TMA}^{+}$, nearly spherical packing becomes possible to make SBA-1.

Within the $\mathrm{pH}$ range of 1.0-2.0 and under dilute conditions, the slow reaction rate leads to a long induction time for gel formation; and the induction time decreases with decreasing $\mathrm{pH}$. This is because the silica condensation rate and surface charge of silica oligomers increases with decreasing $\mathrm{pH}, \mathrm{pH}=$ 2 being the slowest. To examine the $\mathrm{pH}$ value-effect on morphology, we recorded SEM micrographs (Hitachi S-800 operated at an accelerating voltage of $20 \mathrm{keV}$ ). Under lowmagnification, one can find the samples prepared at different $\mathrm{pH}$ conditions have different crystal shapes, and the crystal morphology is highly homogeneous (Fig. 2). For a clear observation of the dominant crystal morphology in each sample, Fig. 2 also displays the representative high-magnification SEM micrographs of the SBA-1 mesoporous silica products. The shape of the SBA-1 mesoporous silica synthesized at $\mathrm{pH}=1.0$ is in a spherical form. On increasing the $\mathrm{pH}$ value to 1.5 , decaoctahedron crystals were found. The square and hexagonal crystal planes are clear enough to be indexed as $\{100\}$ and $\{110\}$ faces. As the $\mathrm{pH}$ value is increased to 1.8 , the silica condensation rate gets even slower, and then the SBA-1 crystals adopt a truncated-cube form with a smaller hexagonal
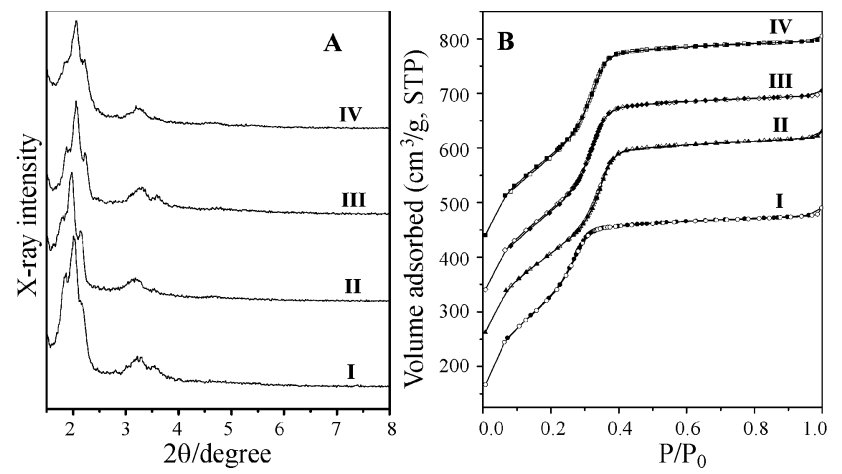

Fig. 1 XRD patterns (A) and $\mathrm{N}_{2}$ adsorption-desorption isotherms (B) of the calcined mesoporous silica synthesized from $\mathrm{C}_{18} \mathrm{TMACl}$-sodium silicate- $\mathrm{H}_{2} \mathrm{O}$ at $30{ }^{\circ} \mathrm{C}$ in aqueous solutions at: $\mathbf{I} \mathrm{pH}=1.0 ;$ II $\mathrm{pH}=1.5$; III $\mathrm{pH}=1.8 ; \mathbf{I V} \mathrm{pH}=2.0$. 

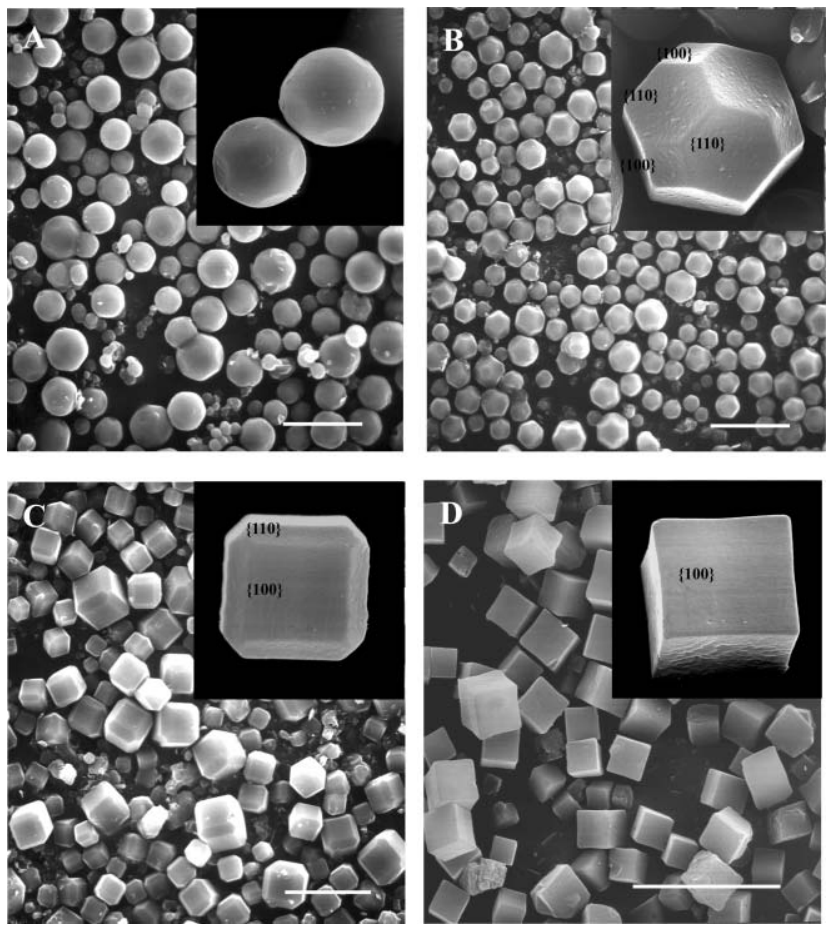

Fig. 2 Representative low-magnification SEM micrographs of the calcined mesoporous silica of the samples in Fig. 1. A Sample I ( $\mathrm{pH}=$ 1.0); B Sample II ( $\mathrm{pH}=1.5)$; C Sample III ( $\mathrm{pH}=1.8)$; D Sample IV $(\mathrm{pH}=2.0)$. The insets are the high-magnification SEM images of the representative SBA-1 mesoporous silica crystals. The scale bar = $15 \mu \mathrm{m}$.

$\{110\}$ face. When the $\mathrm{pH}$ value is at 2.0 , the crystal shape transforms to cubic crystals without the $\{110\}$ faces.

Here, we try to explain the evolution of the crystal shape based on the rate of crystal growth. The growth of the SBA-1 mesoporous silica crystal can be regarded as a kind of selfassembly process in the sense that the surfactants and silica species recognize one another in solution and find their optimum orientation in the time available. First, the oligosilicate species are distributed in solution near $\mathrm{pH}=2.0$ and they do not condense appreciably. Then, the surfactant aggregates and silicate species self-assemble in solution leading to catalyzed silica condensation. The faster condensation rate at $\mathrm{pH}=1.0$ results in fast and isotropic growth in all directions leading to mesoporous silica spheres. As the $\mathrm{pH}$ value is closer to the IEP of silica, the slower silica-surfactant condensation rate allows differentiation of the different surfaces of the crystal. From the viewpoint of crystallization kinetics, the crystal morphology is determined by the relative rates of growth of different crystal faces, with the slow-growing surfaces dominating the final form. ${ }^{21}$ Because the silicasurfactant interaction strength fundamentally depends on the $\mathrm{pH}$ value, we can reasonably assume that $\mathrm{pH}$-modification on the crystal habits of the SBA- 1 crystals makes the growth rate of (100) and (110) crystal faces different. At $\mathrm{pH}$ values appreciably lower than the IEP of silica, the surfactant would interact more strongly and thus more evenly with silicate on the (110) and the (100) plane, which promoted more isotropic growth. As the $\mathrm{pH}$ is near 2.0, the IEP of silica, growth rates at both the (100) and (110) decrease, but the relative difference between them is big, with the (100) face being the slowergrowing one. One thus has a dominating (100) surface at the end. The disappearing (110) surface as the $\mathrm{pH}$ is raised towards 2.0 rather convincingly illustrates the $\mathrm{pH}$ control of crystal growth.

In brief, the kinetic crystallization model provides a strategy to design the desired mesoporous silica crystals. The detailed kinetics of crystallization of self-assembled surfactant-silica may be quite complicated. Many other experimental factors, ${ }^{22}$ including the change of surfactant chain length, concentration of surfactant, and the addition of polyelectrolytes ${ }^{23}$ and temperature may also influence the formation mechanism of the SBA-1 mesoporous silica crystals. With well-controlled crystal shapes, the 3-D channeled cubic mesoporous silica crystal may be considered for various applications in adsorption, separation and catalysis.

\section{Acknowledgements}

This work is supported by the National Science Council (NSC92-2113-M-006-015) and the Ministry of Education of Taiwan.

\section{Notes and references}

$\dagger$ Synthesis: Dilute acidified-sodium silicate solution was prepared by rapidly pouring $52.75 \mathrm{~g}$ of sodium silicate solution (sodium silicate : $\left.\mathrm{H}_{2} \mathrm{O}=1: 9.5\right)$ into $250 \mathrm{~g}$ of $(0.50-0.30) \mathrm{M}$ aqueous $\mathrm{H}_{2} \mathrm{SO}_{4}$. The $\mathrm{pH}$ value of the acidified-sodium silicate solution was adjusted to the desired range of 1.0 to 2.0. Combining the sodium silicate solution with a suitable amount of $\mathrm{C}_{18} \mathrm{TMACl}$ solution, a transparent solution was obtained initially, which then slowly became opaque. The gel composition in molar ratio is: $1.0 \mathrm{C}_{18} \mathrm{TMACl}: 2.15 \mathrm{SiO}_{2}: 1.67$ $\mathrm{NaOH}:(4.35-1.30) \mathrm{H}_{2} \mathrm{SO}_{4}: 3878.26 \mathrm{H}_{2} \mathrm{O}$. After an aging time of 4 days, the $\mathrm{pH}$ value of the gel solution remained constant and a white precipitate was formed. Following filtration, washing and drying the organic template was removed by calcination at $560^{\circ} \mathrm{C}$ under air.

1 J. Kim, S. K. Kim and R. Ryoo, Chem. Commun., 1998, 259.

2 M. Kaneda, T. Tsubakiyama, A. Carlsson, Y. Sakamoto, T. Ohsuna and O. Terasaki, J. Phys. Chem. B, 2002, 106, 1256.

3 X. Liu, B. Tian, C. Yu, F. Gao, S. Xie, Bo Tu, R. Che, L. Peng and D. Zhao, Angew. Chem., Int. Ed., 2002, 41, 3876.

4 C. Yu, B. Tian, J. Fan, G. D. Stucky and D. Zhao, J. Am. Chem. Soc., 2002, 124, 4556.

5 Z. Zhang, B. Tian, S. Shen, J. Fan, Bo Tu, Q. Kong, F. Xiao, S. Qiu and D. Zhao, Chem. Lett., 2002, 584.

6 S. Che, Y. Sakamoto, O. Terasaki and T. Tatsumi, Chem. Lett., 2002, 214.

7 S. Che, Y. Sakamoto, O. Terasaki and T. Tatsumi, Chem. Mater. 2001, 13, 2237.

8 S. Che, S. Kamiya, O. Terasaki and T. Tatsumi, J. Am. Chem. Soc., 2001, 123, 12089.

9 A. Sayari, S. Hamoudi, Y. Yang, L. Moudrakovski Igor and R. Ripmeester John, Chem. Mater., 2000, 12, 3857.

10 M. P. Kapoor and S. Inagaki, Chem. Mater., 2002, 14, 3509.

11 I. Braun, G. Ihlein, F. Laeri, J. U. Nöckel, G. Schulz-Ekloff, F. Schüth, U. Vietze, Ö. Weiß and D. Wöhrle, Appl. Phys. B. Lasers Opt., 2000, 70, 335.

12 M. Ganschow, G. Schulz-Ekloff, M. Wark, M. Wendschuh-Josties and D. Wöhrle, J. Mater. Chem., 2001, 11, 1823.

13 Z. R. Tian, J. Liu, J. A. Voigt, B. Mckenzie and H. Xu, Angew. Chem., Int. Ed., 2003, 42, 413.

14 Y. Sakamoto, M. Kaneda, O. Terasaki, D. Zhao, J. M. Kim, G. D. Stucky, H. J. Shin and R. Ryoo, Nature, 2000, 408, 449.

15 S. Che, Y. Sakamoto, O. Terasaki and T. Tatsumi, Chem. Mater., 2001, 13, 2237.

16 M. P. Kapoor and S. Inagaki, Chem. Mater., 2002, 14, 3509.

17 S. Che, S. Lim, M. Kaneda, H. Yoshitake, O. Terasaki and T. Tatsumi, J. Am. Chem. Soc., 2002, 124, 13962.

18 A. Vinu, V. Murugesan and M. Hartmann, Chem. Mater., 2003, 15, 1385 .

19 S. Guan, S. Inagaki, T. Ohsuna and O. Terasaki, J. Am. Chem. Soc., 2000, 122, 5660 .

20 S. Inagaki, S. Guan, Y. Fukushima, T. Ohsuna and O. Terasaki, J. Am. Chem. Soc., 1999, 121, 9611.

21 S. Mann, Biomineralization Principles and Concepts in Bioinorganic Materials Chemistry, Oxford University Press, New York, 2001.

22 H. P. Lin and C. Y. Mou, Acc. Chem Res., 2002, 35, 927.

23 C. C. Pantazis and P. J. Pomonis, Chem. Mater., 2003, 15, 2299. 